\title{
O signo gráfico, chave da aprendizagem da escrita
}

\section{Graphic sign, the key for literacy}

\author{
Élie Bajard ${ }^{1}$
}

\section{RESUMO}

Os sucessivos planos de alfabetização lançados no Brasil nos últimos 25 anos não vêm reduzindo a taxa de analfabetismo funcional, e, por outro lado, a escola tem fracassado no ensino da ortografia. Uma das causas desses dois insucessos provém da concepção fonológica da aprendizagem da escrita. Tal diagnóstico se apoia em experimentações nas quais crianças que moram nas periferias das cidades, além de conviverem com a literatura infantil, são convidadas a se apropriar de seu nome gráfico e das primeiras palavras, independentemente de correspondências fonográficas. Elas adquirem uma consciência gráfica por meio da qual percebem o vínculo dos caracteres com o signo gráfico e com a compreensão. Ao aprender a compreender antes de pronunciar, as crianças deixam de estar sujeitas a pronunciar sem compreender, ou a escrever como pronunciam.

PALAVRAS-CHAVE: Fracasso escolar. Alfabetização. Signo gráfico. Compreensão. Caracteres.

\begin{abstract}
On the one hand, the successive literacy plans launched in Brazil in the last 25 years have not reduced the functional illiteracy rate; and on the other, schools have failed to properly teach spelling. One of the causes of these two failures comes from the phonological conception of literacy. The realization of such issue is supported by trials in which children living in the outskirts of cities, in addition to being daily exposed to children's literature, are invited to take ownership of their written names and the first words, regardless of whether they correspond phonologically. They
\end{abstract}

\footnotetext{
${ }^{1}$ Doutor em Linguística pela École des Hautes Études en Sciences Sociales, de Paris. Atuou como adido linguístico da Embaixada da França no Brasil. França. E-mail: emebaj@uol.com.br
} 
acquire a graphical consciousness by being able to perceive the relationship of the characters with a graphic sign and through understanding. By learning to understand before pronouncing, children are no longer subject to pronouncing words without understanding their meaning, or writing as pronounced.

KEYWORDS: Schoolfailure. Literacy.Graphic sign. Understanding.

Characters.

Duas mudanças recentes transformaram profundamente a relação da criança com a língua escrita: o surgimento da literatura infantil na última metade do século passado e, atualmente, a expansão dos aparelhos nômades (BAJARD; ARENA, 2015). Utilizarei aqui o termo genérico "tablet" para designar smartphones e tablets.

O encontro inicial com a escrita não ocorre mais por meio das cartilhas entregues no primeiro ano da escola fundamental, pois a criança engatinha em livros de literatura em casa, antes de saber andar. Ela tem acesso, portanto, a uma grafia não escolarizada, mas editada em caixa dupla - maiúsculas e minúsculas -, com espaços em branco, isto é, a uma escrita em funcionamento. A criança encontra textos coesos e não apenas palavras ou frases isoladas, como é o caso na cartilha.

Como a criança lida no dia a dia com uma escrita autêntica dentro do livro - e não por meio de uma forma escolar adulterada -, o professor perde a disposição de iniciar o processo alfabetizador pela escolha do livro didático. A matéria gráfica do "álbum" de literatura infanto-juvenil - que combina texto e imagem - se expõe aos olhos da criança por meio da sua complexidade. Esta língua visível (SMITH, 1999); não acessível ao cego; silenciosa (FOUCAMBERT, 2008); compreendida pelo surdo; e "plena" (BAJARD; ARENA, 2015), na qual a minúscula não é ostracizada; oferece-se aos olhos para ser conquistada.

A invenção da informática é a segunda mudança, ainda mais recente. $\mathrm{O}$ processador de texto modificou a maneira de escrever. Assim, mediante a 
função copiar/colar, quem escreve intervém no corpo do texto sem deixar traços dessa intervenção. Graças a essa função, o computador superou a máquina de escrever do século XIX, a qual, por sua vez, já tinha derrubado a hegemonia da pena e do lápis.

A máquina informática mais recente, o tablet, com seu teclado na tela apresentando não letras, mas caracteres, transforma a prática da escrita dos computadores anteriores e, em breve, revolucionará as maneiras aprender.

O tablet oferece um teclado tátil não só de letras, mas reúne todos os elementos da ortografia, com ou sem acento (diacrítico), diretamente acessíveis a um toque único do dedo. Além disso, esse computador de bolso possibilita, mediante o ditado, transformar um texto sonoro em texto gráfico, assumindo o papel do escrivão-escravo grego que colocava no pergaminho os discursos proferidos por seu mestre. Enfim, a produção da escrita com esse instrumento aproxima a elaboração de palavras gráficas das operações necessárias à sua leitura, já que a partir da geração de alguns elementos, a máquina, antecipando a ortografia, apresenta aos olhos três ou quatro palavras potenciais, entre as quais o usuário seleciona aquela que é pertinente.

Quem utiliza os transportes coletivos das grandes cidades percebe que muitos usuários estão ocupados com seu aparelho multimídia portátil não somente para escutar música, mas também para ler e escrever. Além disso, nos escritórios ou em casa, vários profissionais dedicam mais tempo ao computador do que à conversa com parceiros ou parentes.

Dado que a escrita conquistou tamanha audiência, parece difícil considerar simplesmente que "a escrita mapeia a fala" (CAPOVILLA, 2002, p. 84), desconsiderando sua autonomia. Podemos, também, avançar o argumento inverso. $\mathrm{Na}$ prática da proferição, o texto gráfico dá origem ao texto sonoro (BAJARD, 2007). Assim como a fala, a escrita é uma língua em si mesma que serve para se comunicar, se expressar, jogar, pensar. Infelizmente, o ensino de uma escrita apta a cumprir essas funções não tem sido proporcionado à totalidade dos jovens do país; nem pela escola, nem 
pela sociedade.

Neste artigo, queremos, em um primeiro momento, fazer um balanço da situação do domínio da língua escrita pelos jovens a partir não somente das avaliações formais, mas também das representações sociais dos seus atores e beneficiários. Em um segundo momento, com base em uma experimentação sediada em instituições não governamentais - Projeto Arrastão na zona Sul e Arca do Saber na favela Vila Prudente de São Paulo - ou no ensino público - Educação Infantil e Ensino Fundamental do Município de Marília (SP), todas localizadas na periferia das duas cidades, pretendemos mostrar que é possível e desejável instaurar, desde o início da aprendizagem da língua escrita nas crianças de famílias populares uma compreensão baseada não em signos sonoros a serem atingidos pela transposição das letras em sons, mas sim no vínculo que os signos gráficos estabelecem entre os caracteres e o significado.

\section{Fracasso da alfabetização}

Regularmente, jornais e revistas relatam os péssimos resultados obtidos pelos alunos brasileiros nas provas nacionais e internacionais.

Uma avaliação nacional, a Prova Brasil, por exemplo (INEP, 2015), administrada pelo Ministério da Educação (MEC) e efetuada nos quinto e nono anos, calculou que $24,84 \%$ dos alunos do quinto ano não atingem o terceiro dentre nove níveis relativos ao domínio da escrita. Esse terceiro nível é caracterizado pelas competências seguintes:

- Localizar informação explícita em contos e reportagens;

- Localizar informação explícita em propagandas com ou sem apoio de recursos gráficos;

- Reconhecer relação de causa e consequência em poemas, contos e tirinhas;

- Inferir o sentido de palavra, o sentido de expressão ou o assunto, em 
cartas, contos, tirinhas e histórias em quadrinhos com o apoio de linguagem verbal e não verbal.

Outra avaliação, internacional dessa vez, o Programa Internacional de Avaliação de Estudantes (Pisa, sigla em inglês para Programme for International Student Assessment), é aplicado pela Organização para a Cooperação e Desenvolvimento Econômico (OCDE) a 65 nações e coloca o Brasil na $55^{\mathrm{a}}$ posição (PISA, 2014). O resultado é pouco glorioso, considerando-se que todas as nações confrontam o analfabetismo funcional e enfrentam dificuldades para reduzi-lo.

Ora, as competências exigidas pelas avaliações citadas medem a capacidade de compreensão dos estudantes. Essa escolha se justifica na Prova Brasil pela pretensão de medir o desempenho dos alunos do quinto e do nono ano da escola fundamental, isto é, de alunos já distantes dos anos de alfabetização.

Quando o Pisa, por sua vez, avalia "se os alunos sabem utilizar as lições aprendidas na escola para se virar na vida" (BAUDELOT C., ESTABLET, 2009, p.25, tradução nossa), ele está medindo as capacidades de jovens de países que usam sistemas gráficos diferentes: alfabético no Brasil, consonântico em Israel ou na Jordânia, ou ideográfico no Japão.

A própria criação do conceito de analfabetismo funcional pelos organismos internacionais concretiza a discrepância entre o ensino do sistema alfabético e a expectativa da sociedade, que espera uma formação completa do usuário da escrita. A Organização das Nações Unidas para a Educação, a Ciência e a Cultura (Unesco) definiu que "é considerada alfabetizada funcional a pessoa capaz de utilizar a leitura e escrita para fazer frente às demandas de seu contexto social e usar essas habilidades para continuar aprendendo e se desenvolvendo ao longo da vida” (IPM, 2015).

Assim, o analfabeto funcional passou por uma alfabetização não funcional, isto é, inútil. A existência de tal hiato não deveria inocular dúvidas em relação ao pensamento hegemônico segundo o qual o domínio do 
alfabeto é o caminho imprescindível para formar o usuário da escrita?

\section{Queixa dos professores}

Além das avaliações formais, é importante levar em conta a opinião dos atores da escola e escutar a queixa constante emitida pelos professores sobre seus alunos: “sabem ler, mas não entendem”. Essa fórmula concisa corrobora os resultados mencionados acima e traduz a dupla injunção à qual os professores são submetidos: ensinar a pronunciar e levar a compreender. Mediante tal aforismo, os professores destacam dois fatos. De um lado, a eficiência da sua atuação é reconhecida: os alunos sabem transformar letras em sons, capacidade exigida pela instituição escolar, o que equivale, na língua comum, a "sabem ler".

Mas o aforismo expressa também a insatisfação de tais docentes, que não conseguem satisfazer a demanda da sociedade: os alunos "não entendem". Por meio dessa queixa, os professores explicitam um mal-estar profundo, nascido do equívoco entre sua atuação e a cobrança social.

Essa dupla injunção não é apenas social ou institucional. Ela ecoa o postulado básico da Linguística Clássica enunciado por Saussure: "língua e escrita são dois sistemas distintos de signos; a única razão de ser do segundo é representar o primeiro." (SAUSSURE, 1969, p. 34). Se nessa visão a contribuição da escrita para a comunicação e para o pensamento não é negada (isso seria difícil para um linguista), ela se realiza tão somente sob o reino da língua sonora. Desse modo, vista tão somente como réplica da língua oral transposta pelo alfabeto, a escrita não se beneficia plenamente do estatuto de língua.

\section{Os métodos}

A escola se vale dessa visão fonocêntrica (DERRIDA, 1999) da Linguística Clássica quando seus professores convidam os alunos, em 
situações de leitura, a transpor a escrita em língua oral, isto é, a pronunciar o texto escrito para abrir o acesso ao significado, "falando consigo" (CAPOVILLA, 2002, p. 54). No relatório encomendado pela Câmara dos Deputados ao Painel Internacional de Especialistas em Alfabetização Infantil, lemos:

Depois que o poeta Milton se tornou cego e resolveu reler os clássicos, ele ensinou suas filhas a decodificar textos em Grego, embora não pudessem compreender uma só palavra desse idioma. Podemos afirmar que Milton estava lendo? Não, ele simplesmente ouvia a leitura feita por sua filha. Mesmo se fosse analfabeto, mas soubesse o Grego, ele poderia compreender. E as filhas de Milton, estariam lendo? Naturalmente que sim, estavam simplesmente lendo. (MORAES apud CAPOVILLA, 2005, p. 20).

Ao definir o ato de ler pela pronúncia, tanto Moraes quanto a queixa dos professores excluem de tal ato a compreensão. Por essa visão, é possível ler, isto é, pronunciar, sem compreender. Esta maneira de encarar a leitura não pode atender os professores atentos a proporcionar o domínio do significado, nem as instâncias internacionais que avaliam o "saber ler" com base em testes de compreensão.

Apesar de ser menos radical do que Moraes, Capovilla, líder brasileiro do método fônico, apresenta uma concepção semelhante. Segundo ele, o ato de ler inclui a compreensão, mas ela se origina na língua oral, conforme o postulado saussuriano reformulado em "a escrita é um código derivado da língua falada" (CAPOVILLA, 2002, p. 34).

Para Capovilla, as correspondências fonográficas - relações entre letras e sons - permitem construir o signo sonoro compreendido pelo locutor. Trata-se de um exercício em duas operações: uma "aplicação de regras de correspondência grafofonêmica seguida por um acesso ao significado [...] alcançado mais tarde quando a pronúncia da palavra [...] ativa o sistema semântico" (CAPOVILLA, 2002, p. 76). Por ser conformar à visão 
tradicional, esse procedimento é considerado simples. No entanto, ele instala duas armadilhas na aprendizagem.

A primeira pode ser exemplificada pelo caso de uma menina de 11 anos que não consegue entender a palavra 'bolo' inscrita sobre uma caixa de papelão recebida no final de uma festa de escola. Por não levar em conta o acento tônico da palavra paroxítona, não marcado por um diacrítico, a menina pronuncia uma sequência de fonemas sem conseguir inferir a "música" (prosódia) da palavra e, consequentemente, sem acessar o significado sonoro.

A segunda armadilha, a nosso ver, é mais grave, por ser mais insidiosa. Se essa menina tivesse emitido a prosódia da palavra, teria compreendido o signo sonoro reconstituído. Pela pronúncia, teria cumprido laboriosamente um ato de leitura. No entanto, esse sucesso deixaria de lado o signo gráfico, que não teria sido decodificado. Utilizaremos a terminologia acima, que leva em conta o nosso pressuposto de que o signo linguístico se manifesta com um mesmo significado em dois universos distintos da percepção, por meio de dois significantes que constituem o signo sonoro e o signo gráfico.

\section{Fracasso na ortografia}

A essa queixa dos professores, "sabem ler, mas não entendem", podemos acrescentar outra, que remete à ortografia dos alunos: eles "escrevem foneticamente". As representações sociais, tanto da sociedade quanto dos docentes - seria importante obter dados confiáveis para conferir ou não o senso comum -, manifestam um domínio insuficiente da ortografia da língua portuguesa, apesar dos vários anos de ensino dessa matéria no currículo da escola fundamental. A dificuldade de utilizar a crase, por exemplo, torna-se emblemática do massacre da ortografia pelos jovens. De fato, ao desprezar esse diacrítico, eles traduzem por escrito, de maneira econômica, a correspondência fonográfica interiorizada durante o período de 
alfabetização. Por que então escola e sociedade se escandalizam com uma ortografia que obedece ao código fonológico ensinado nos anos anteriores?

Os professores são, assim, o alvo de duas críticas contraditórias. De um lado, os adolescentes "sabem ler, mas não entendem"; de outro, "escrevem como escutam". Esses dois fracassos - na alfabetização e na ortografia - são, muitas vezes, analisados separadamente. Haveria inicialmente o tempo da alfabetização e do domínio do sistema alfabético. Uma vez concluída essa fase, seria necessário aperfeiçoá-la, reconhecendo que não é bem assim... que é preciso ir mais além... e obedecer a novas exigências como, por exemplo, colocar um agá na palavra "homem". Teria chegado então o tempo da ortografia!

Há o tempo das relações fonográficas e há o tempo da grafia certa $($ orto $=$ direto $)$. $\mathrm{O}$ primeiro corresponde ao início da escola fundamental; o outro, aos anos seguintes. Até na abordagem construtivista de Emília Ferreiro, a ortografia é a última fase da conquista da escrita e ocorre depois da passagem pelas anteriores: pré-silábica, silábica, alfabética. A fase ortográfica é, nessa visão, apenas um enfeite final (FERREIRO, 1994). No entanto, será que os alunos não se dão conta da contradição entre a instrução do primeiro ano - escrever o que se escuta - e a do quinto ano duvidar dela? Podemos avançar que os alunos erram a ortografia porque a escola apresenta essa última apenas como um conjunto de exceções que limita o princípio alfabético, sem perceber sua função geradora de significado ('rio'//'riu').

Se tanto o fracasso da alfabetização quanto o da ortografia - na escrita infantil /voakaza/ o vínculo visual com o significado é rompido - se traduzem como um déficit de compreensão, podemos inferir que essas duas dificuldades encontradas no ensino da língua escrita não são fenômenos isolados a serem enfrentados separada e sucessivamente, mas resultam de uma concepção única da escrita que despreza a função discursiva. É legítimo pensar que, ao ensinar as correspondências entre letras e sons marcadas por uma "infidelidade radical" (DERRIDA, 1999, p. 48), o alfabetizador despreza 
a função discursiva dos elementos gráficos, enquanto o aluno, educado para pronunciar, não descobre a função semântica da ortografia.

\section{Alternativa}

Há mais de dez anos no Projeto Arrastão, instituição apresentada no início desse artigo, é praticada diariamente a chamada Sessão de Mediação, por meio da qual a criança, desde os seis meses de idade, manuseia livros, interpreta suas imagens e escuta seus textos proferidos por mediadores (BAJARD, 2007). Depois de ter herdado a língua falada dos seus pais, ela recebe - segundo legado - a língua escrita, mediante a literatura infantil. Desse modo, a instituição começou a responder ao desafio que emerge do diagnóstico descrito acima: as crianças do Arrastão lidam com textos de literatura antes da idade da alfabetização formal.

Paralelamente, conforme uma tradição da educação infantil, o nome gráfico da criança é entregue em um crachá que apresenta um signo duplo: a grafia do nome e uma figura (CHRISTIN, 2011) constituída por sua fotografia de identidade. Esse evento é festejado no Arrastão pela cerimônia do nome, que pontua a entrada da criança no mundo da escrita. Por participar da consciência de si, a apropriação do nome gráfico provoca em cada pessoa um impacto na vida cotidiana e na construção da personalidade. De fato, o domínio da grafia do nome permite à criança se manifestar no interior do grupo de maneira distinta daquela de que se vale quando usa o nome sonoro.

Mais tarde, a foto é substituída por um totem escolhido cuidadosamente pela criança, antes que o nome gráfico finalmente opere sozinho. A criança passa assim do manuseio de um signo a outro: fotográfico, pictográfico, ideográfico, sem abandonar a função simbólica ao longo desse passo a passo.

\section{Atos de escrita}

Diariamente, as educadoras constroem situações sociais e lúdicas 
colocando em jogo o nome gráfico das crianças. Assim, a aprendizagem da escrita se desenvolve desde o início por meio de sua função discursiva. $\mathrm{O}$ signo visual é convocado na vida infantil em situações singulares não contempladas pela língua oral: o crachá pendurado no cabide é substituído pela mochila de manhã e, inversamente, é trocado à tarde. A tabela de presença é reconstruída cada manhã com tirinhas expondo o dia todo o nome dos presentes e escondendo o nome dos ausentes. Brincadeiras cotidianas são propostas, como a das bexigas que carregam os nomes no ar e são recuperadas no chão pelas crianças antes de serem explodidas. Assim, o procedimento se inscreve dentro de uma "pedagogia ativa" na qual as crianças se apropriam desse primeiro signo graças à sua funcionalidade social.

Mas o crachá, ou a tira, não é somente suscetível de ser lido, mas pode ser também produzido. Para isso, as educadoras confeccionam quebracabeças e convidam as crianças a reconstituir seu nome a partir de duas ou três peças recortadas aleatoriamente. Apesar de a individuação das "letras" não ser levada em conta nesse jogo, esse ato de escrita constitui a primeira assinatura infantil.

Por meio do uso da escrita, as educadoras multiplicam as interações lúdicas, sociais, expressivas, institucionais entre a criança, seus colegas e os adultos que as cercam, propiciando, além do benefício educacional trazido pela atividade, a apropriação da grafia.

\section{Caixa dupla}

$\mathrm{Na}$ medida em que as crianças estão diariamente em contato com o livro de literatura infantil, seria incoerente convidá-las a se apropriarem de uma língua escrita modelada por um formato diferente da matéria encontrada nos livros.

Por esse motivo, propusemos às educadoras que utilizassem uma escrita autêntica nos crachás, valendo-se da caixa dupla, isto é, que 
escrevessem /Rosa/ com inicial maiúscula e minúsculas, e não /ROSA/, que pode designar uma flor. Por não corresponder à cultura escolar, esse formato suscitou resistências iniciais por parte das educadoras. No entanto, algumas aceitaram o desafio e começaram a escrever os nomes de seu grupo em caixa dupla.

A constituição dos crachás destacou a estranheza dos nomes das crianças da periferia, tais como 'Bridgith', 'Isabelly', 'Thaylla'. Além de insólitos na oralidade, eles se singularizavam na grafia por letras duplas ou "mudas". Ao considerarem tanto o nome 'Thaylla', pouco ortodoxo, quanto 'Alina' e 'Bruno', fonológicos, as educadoras observaram rapidamente que a grafia não podia ser inferida com base na oralidade, nem servir de ponto de partida para induzir as primeiras correspondências fonográficas. Escrever /Thaylla/ implicava submissão à arbitrariedade da ortografia por parte tanto das educadoras quanto das crianças.

Um benefício imediato apareceu. Ao atribuir um visual específico ao nome próprio, a caixa dupla o singulariza melhor do que a caixa alta. 'Margarida' se distingue de 'MARGARIDA' pela maiúscula à esquerda, por uma haste descendente, outra ascendente, engendrando uma silhueta singular - como um velame de navio (ALAIN, 1978) -, enquanto os nomes em caixa alta formam sempre retângulos. Ficamos surpreendidos de observar que, graças a esse destaque da letra inicial, as crianças adotam rapidamente o sentido da escrita, da esquerda para a direita.

\section{Configuração}

Por intermédio desse manuseio, as crianças perceberam que o nome é constituído de elementos menores, que formam um conjunto específico. Uma vez dominado esse primeiro signo ideográfico, elas foram convidadas a cortar o nome próprio em elementos, fazendo passar a tesoura nos espacinhos brancos entre "as letras" e os recolheram em uma caixa individual, réplica daquela do tipógrafo. Esse recorte levou os participantes 
do projeto a duas observações:

- o recorte de 'Talita' distingue os componentes /T/ e /t/; esses dois elementos pertencem à mesma letra do alfabeto, por não serem permutáveis não têm a mesma função discursiva.

- na perspectiva das crianças de 3 anos, o conjunto /T-h-a-y-l-l-a/ está ligado a uma menina do grupo e nenhum elemento desse nome pode ser excluído ou permutado sem destruir o vínculo com essa menina; 'Thaylla' é assim uma configuração de unidades, sendo que cada uma delas participa do significado.

É esse traço etnológico - a especificidade dos nomes das crianças da periferia - que fez surgir em nossa experimentação, na raiz da aprendizagem, a preeminência do código ortográfico sobre o sistema alfabético. Estamos convencidos que essa experimentação não teria ocorrido no centro da cidade com crianças chamadas Bruno ou Fernanda.

Nessa abordagem infantil do nome, a ortografia cria significado, independentemente do valor sonoro dos seus componentes. Isso é destacado por dois fatos:

- nenhum valor sonoro dos elementos gráficos é dominado pelas crianças dessa idade;

- alguns desses componentes, como /l1/ em lugar de /l/, /y/ em lugar de /i/ ou /h/ não possuem valor sonoro.

Nessa situação de aprendizagem, o postulado fonocêntrico é excluído do jogo, já que não é o valor sonoro das letras que permite o acesso ao significado, mas o "código ortográfico" que se instala no centro do processo. Desse modo, a criança compreende o nome escrito dos colegas antes de pronunciá-lo. Ela extrai o sentido de um signo visual, herdeiro da figura traçada pelo homem, talvez antes mesmo de ele ter conquistado a fala. 
Não seria absurdo supor, ao contrário do senso comum, que o traçado de figuras na areia, ou sobre um suporte similar, pela primeira vez, teria fornecido ao homem a intuição daquilo que viria a ser, muito mais tarde, a escrita (CHRISTIN, 2011, p. 23).

Configurados por componentes ortográficos, esses signos são interpretados. A leitura não se realiza mais por uma operação dupla: a extração da pronúncia e a extração do sentido. A dicotomia entre pronúncia e compreensão é abolida. Não existe mais uma máscara fonológica entre ortografia e significado. O processo se torna um ato único e silencioso de compreensão a partir da ortografia.

\section{Consciência gráfica}

Assim, Lívia obtém pelo recorte de seu nome cinco elementos diferentes (L-í-v-i-a), lí/ e li/ sendo elementos distintos. Convidada a reconstrui-lo, Lívia faz questão de colocar cada elemento no seu lugar, sem permutar o /í/ pelo /i/, o que inviabilizaria o seu nome.

Depois da primeira fase, na qual a criança se apropriou de uma silhueta, ou seja, de um ideograma, ela é convidada a recortar seus componentes ortográficos, tornando-os móveis. Ela pode, assim, manuseá-los muito antes de possuir a motricidade fina necessária ao manuseio do lápis, um "instrumento com ponta criado em uma sociedade não digital" que requer "movimentos de rotação e de translação" (ARENA, 2014, s.p.), inúteis no uso do tablet.

Ao perceber que a configuração/L-í-v-i-a/ remete a ela mesma, que é constituída de unidades que obedecem a uma ordem linear imposta pela língua, que os componentes de Livia podem ser utilizados também por outros nomes e pertencem a um conjunto limitado, a menina Lívia adquire uma consciência gráfica ${ }^{2}$.

\footnotetext{
${ }^{2}$ Expressão utilizada por Jean Foucambert durante conversa pessoal.
} 
O surgimento dessa competência infantil se repete com os colegas. João Victor - nome pronunciado [vitor] - se rebela quando o adulto omite o /c/. Ao observar Victor fazer questão de incluir o /c/ "mudo" de seu nome, percebemos que o menino tomou consciência da função discursiva do /c/, que, no entanto, é isento de valor sonoro.

Rapidamente as educadoras observaram que o manuseio da caixa dupla facilitava a apropriação do nome. Consciente das novas relações sociais geradas por essa conquista, as crianças se implicavam nos atos de língua escrita propostos na sala de aula. O investimento em energia e em tempo realizado pelas educadoras era retribuído pelos êxitos das crianças e pelo entusiasmo de todos. Esses benefícios se tornaram o motor da contaminação da experimentação com colegas que começaram então a aderir à nova prática.

\section{Primeira palavra}

Depois da conquista do nome próprio, a criança, ao confrontar um texto escrito desconhecido, é convidada a investigá-lo para identificar uma primeira palavra. Com base em um poema intitulado "A borboleta", por exemplo, ilustrado por imagens desse mesmo inseto, a criança "identifica" seu primeiro substantivo comum. Ela relaciona o conjunto de traços entre dois espaços em branco ao inseto colorido que conhece. Como ocorreu no caso do nome próprio, essa operação consiste em aproximar uma configuração gráfica de uma palavra conhecida na língua falada. No caso do nome próprio, a identificação foi desvelada na cerimônia do nome, pelo educador que pontuava: "esse é o seu nome". No caso da primeira palavra, a identificação é o resultado de uma investigação infantil no interior de um texto. Nas duas situações - do nome próprio e da primeira palavra -, tratase de vincular uma ortografia ainda desconhecida diretamente a um significado. 


\section{Código tipográfico}

A identificação da primeira palavra supõe a individuação de sua configuração, seu destaque no meio do texto. Sua extração é possibilitada por um componente gráfico até então não observado, que delimita a palavra de ambos os lados: o_espaço_em_branco. Ora, esse elemento gráfico é o mais frequente da escrita portuguesa e representa $20 \%$ dos componentes de qualquer texto. É nesse branco que se tecem as relações das palavras entre si: entre o verbo e seu sujeito, entre o substantivo e seu adjetivo ou seu artigo, ou seja, as relações gramaticais.

É necessário também lembrar nossa vontade de introduzir a minúscula dentro do nome próprio desde o início do processo. No entanto, nem o espaço em branco nem a minúscula dizem respeito à pronúncia. Ao inserir esses elementos "mudos", estamos ampliando a dimensão ortográfica comum. Trata-se agora de levar em conta outro código, em uso desde a invenção da imprensa por Gutenberg: o código tipográfico com seus caracteres.

Exemplifiquemos a afirmação com outros casos de língua: na palavra 'homem', que o alfabetizando pode encontrar em álbuns, percebemos que as quatro letras /omem/, que se relacionam a sons, precisam da letra /h/, "muda", para que exista a ortografia da palavra. Aqui, a análise de Vigostki sobre a ordem sonora nos ajuda:

O traço mais importante do som da fala humana é o fato de que esse som, que desempenha uma função determinada de som, está relacionado a um significado, mas como tal é um som desprovido de significado [...]. Assim, a unidade da fala vem a ser, no som, uma nova concepção, não de um som isolado mas de um fonema, isto é, de uma unidade fônica indecomponível, que conserva todas as propriedades básicas de todo o aspecto sonoro da fala com função de significação. (Vigotski, 2010, p. 15).

Assim, se cada um dos três sons do signo sonoro é "uma unidade 
fônica indecomponível, que conserva todas as propriedades básicas de todo o aspecto sonoro da fala com função de significação", é evidente que cada um dos três grafemas, $/ \mathrm{o} /+/ \mathrm{m} /+/ \mathrm{em} /{ }^{3}$, por pertencerem à ordem visual, não "conserva[m] as propriedades básicas de todo o aspecto sonoro da fala" e, consequentemente, não possuem uma "função de significação". Pelo menos, ao representar o fonema, o grafema possui, sim, um valor sonoro ${ }^{4}$.

$\mathrm{O} / \mathrm{h} /$ - que por não possuir valor sonoro não é grafema - é necessário à ortografia da palavra gráfica. Assim, o /h/, "indecomponível [...] conserva todas as propriedades básicas de todo o aspecto" visual do signo gráfico "com função de significação".

Então, é lógico dizer que os três grafemas $-/ \mathrm{o} /+/ \mathrm{m} /+/ \mathrm{em} /-\mathrm{de}$ 'homem' possuem um valor sonoro, mas não uma função de significação no universo acústico, enquanto o elemento visual /h/, sem valor sonoro, possui uma "função de significação" no universo visual, isto é, uma função discursiva.

Tal raciocínio dá conta da irritação do menino Victor quando o adulto tira do nome dele o /c/ desprovido de valor sonoro. Victor conhece a função de "significação" desse elemento gráfico sem o qual o seu nome inexiste.

Ora, se o /h/ possui uma função de significação no universo visual da palavra 'homem', por que os outros quatro elementos "indecomponíveis" - /o/ $+/ \mathrm{m} /+/ \mathrm{e} /+/ \mathrm{m} /$ - apreendidos também pelo olho - seriam desprovidos da mesma função?

Observemos agora a seguinte série de palavras: ‘mãe' - 'mão'; ‘pão' 'pio'

A mudança de significado entre uma e a seguinte, se origina na troca de um caractere único (BAJARD, 2014):

- o da terceira posição em 'mãe'/‘mão',

${ }^{3}$ Utilizamos o termo "grafema" para designar o conjunto de letras correspondentes ao fonema. ${ }^{4}$ Objeto do mundo visível, o grafema possui um valor proveniente do mundo acústico, do mesmo modo que uma moeda estrangeira possui aqui um determinado valor, proveniente do outro país. 
- o da primeira posição em 'mão'/"pão',

- o da segunda posição em 'pão'/"pio'.

Em nenhuma dessas trocas o grafema /ão/ é convocado. Como uma sombra do fonema projetada sobre a escrita, o grafema não é definido a partir de uma função discursiva. Ao contrário, na lista acima, apenas um caractere em cada par, isto é, um elemento visual "indecomponível", é responsável pela troca de palavras.

Enfim, no par 'tão'/tio' exterior à nossa série, a troca do /ã/ pelo /i/, elementos visíveis "indecomponíveis", evidencia a eficácia da explicação visual. Por sua "função de significação" a substituição afeta "todo o aspecto" visual da palavra, a qual se pronuncia agora de maneira inteiramente nova: os três fonemas de 'tio' substituíram os dois de 'tão'.

Esses fenômenos ajudam a entender a primazia do código tipográfico sobre o sistema alfabético: qualquer troca de caractere muda a palavra gráfica, com alteração da fonologia ('cão'/'cio') ou sem ('riu'/'rio').

O interesse dessa abordagem é múltiplo:

- o caractere é vinculado ao significado, enquanto a letra e o grafema não são;

- o caractere é uma unidade que se expõe permanentemente aos olhos sem se esvanecer, como ocorre com o fonema que, assim que é dito, se esvai; o caractere permanece disponível para ser tocado, trocado, deslocado e até mordido;

- o caractere silencioso, por ser ligado ao signo visual, possui a característica condizente para fundamentar a leitura silenciosa (SAENGER, 1998).

Assim, podemos postular que a unidade mínima da escrita não é a letra, que possui dois formatos, nem o grafema, que depende do fonema, mas sim o caractere, cuja função provém do seu vínculo com o significado: $o$ caractere é a menor unidade visual capaz de provocar uma mudança de 
significado, como ocorre em 'sol' e 'sou' (BAJARD, 2014).

Essa unidade é definida "pelo papel que assume no interior da escrita, assim como é definido o fonema por seu papel no interior da oralidade" (FOUCAMBERT, 2000, p. 37, tradução nossa). Por operar fora das relações entre som e letra, a prática das crianças engajadas numa escrita com duas caixas evidencia a função discursiva do caractere. A este último pertence a responsabilidade do significado da configuração: a troca de um caractere pode tanto mudar o sentido, 'Rosa' / 'rosa', quanto desqualificá-lo, 'Livia' (sem acento) em lugar de 'Lívia'.

A prática infantil testemunha a aptidão do caractere para metamorfosear o universo evocado ("sabia" - "sabiá" - "sábia"), sensibilizando a criança para a força poética da linguagem sobre o mundo.

\section{Descoberta do texto}

A experimentação pedagógica no Arrastão, que convidou as crianças a uma metodologia duplamente investigativa, já foi detalhadamente descrita (BAJARD, 2012).

Em primeiro lugar, confrontadas a um texto desconhecido, as crianças são convidadas a procurar seu significado mediante operações cognitivas específicas. Nessa busca de sentido, o aprendiz pode enfrentar resistências da língua escrita. Essa situação-problema suscita uma segunda investigação da sua parte, o levantamento de hipóteses a serem conferidas sobre o funcionamento do sistema gráfico. Nas duas investigações, o significado é o motor das operações.

A “descoberta do texto" é, em nossa abordagem, o instrumento central da conquista da língua escrita. Os aprendizes são convidados coletivamente a tomar conhecimento de um texto gráfico desconhecido, nossa definição da leitura. Essa exigência se contrapõe à escuta, mediante a qual o texto é revelado pela percepção auditiva. Uma vez que a compreensão já ocorreu pela audição, o texto escutado não pode mais suscitar a descoberta. 
Desse ponto de vista, o papel do professor de língua escrita e o do mediador de leitura são divergentes. Enquanto o segundo revela o significado do texto aos ouvidos de seus auditores, a descoberta, instrumento do docente, leva o aluno a inferir o significado com base em sua apreensão visual. Entre a prática da escuta e a sistematização da aprendizagem do código gráfico se introduz uma ruptura epistemológica.

Uma vez esgotada a procura do sentido, a proferição do professor faz soar a prosódia do texto sonoro, finalizando a "descoberta" pela revelação da totalidade do significado.

Os benefícios da descoberta do texto são vários. O primeiro consiste em instaurar uma investigação que traz um prêmio imediato: o sentido, até então desconhecido, revela-se no decorrer da procura e atende à curiosidade que suscitou o ato de ler.

Além disso, a descoberta do texto coloca ao dispor do aprendiz uma matéria linguística a ser conquistada, possibilitando um ganho no domínio da escrita. Quando o professor domina essa prática coletiva, ele pode escolher não somente o texto em função das necessidades de seus alunos, como também passa a dispor de meios para avaliar as dificuldades suscitadas pelo léxico. Para isso, o docente recorre a quatro categorias e classifica a palavra em uma escala gradativa. Distingue-se a palavra:

- a ser reconhecida: por ser conhecida nas suas formas, sonora e escrita;

- a ser integrada à língua gráfica: por não ser perfeitamente reconhecível;

- a ser identificada: por ser conhecida apenas em língua oral;

- a ser conceituada: por ser completamente desconhecida (BAJARD, 2012, p. 126).

Diferentemente da leitura solitária, a descoberta do texto se beneficia da colaboração dos colegas e do acompanhamento do professor. No entanto, o papel deste último não se reduz à facilitação do surgimento do significado. 
Mediante perguntas do tipo "Como você sabe?", ele leva os alunos a explicitar as operações cognitivas utilizadas durante o processo.

A descoberta do texto convoca os saberes do aprendiz (sua intuição, sua sensibilidade), mas também seu poder de fazer analogias, inferências e deduções. Deixa aberta a diversidade das entradas no texto. A linearidade é apenas uma delas, pois o contorno visual do texto se expõe aos olhos; estes podem reconhecer uma palavra única, um grupo de palavras, a frase inicial de um parágrafo ou a oração que encerra o texto.

Essa multiplicidade de entradas oferece várias modalidades de exploração do sentido. Com leitores avançados, o professor incentiva os alunos a exprimir a maior parte do sentido do texto incluindo o implícito, isto é, "a informação não visual... [que] já está em sua mente atrás dos olhos" (SMITH, 1999, p. 20) e é inferida pelo leitor experiente.

Diante de leitores iniciantes, esse professor convida a recolher informações parciais e, no caso de crianças pequenas que dominam apenas seu nome, leva-as à identificação de uma única palavra presente no texto. Em todas essas situações, ele não deixa o esforço dos alunos sem a recompensa da compreensão integral, encerrando a descoberta com a proferição do texto completo.

Quando o professor sabe aproveitar as respostas dos alunos e suscitar pistas inesperadas, a classe acaba assumindo o comando da atividade e o significado emergido das diversas facetas do texto é fruto de uma performance coletiva. A descoberta do texto é, de fato, um exemplo límpido de uma pedagogia do "aprender fazendo", pois, os alunos, por meio da condução do professor, aprendem a ler lendo.

\section{Conclusão}

Apresentamos neste artigo argumentos a favor de uma escrita contemporânea e autônoma. Ao abordar uma língua escrita editada em "letras móveis" com caixa dupla e espaço em branco, a criança faz surgir um 
código ortográfico estendido, isto é, um código tipográfico ${ }^{5}$ constituído de caracteres dotados de uma função discursiva dentro do signo visível. Tratase dos mesmos caracteres utilizados pelo tablet. Esse código, que vincula uma configuração visual a um significado, é o código básico da língua escrita e a criança pequena do Arrastão o manuseia muito cedo.

As relações entre grafemas - em [m+ão] são dois - e caracteres - em $/ \mathrm{m}+\tilde{a}+\mathrm{o} /$ são três -, apesar de "amarrarem" juntos o signo gráfico e o signo sonoro, constituem um sistema secundário, pois operam fora do significado. Tanto o código tipográfico na língua visual quanto o código fonológico na língua sonora, nos quais as unidades possuem uma função de significação, têm primazia sobre o sistema alfabético que opera fora dessa função.

Querer lutar contra o analfabetismo funcional supõe colocar em jogo, desde o início da aprendizagem, a "função de significação" de uma escrita considerada um instrumento para se comunicar, se expressar, brincar e pensar. Seria puramente fortuito o fato de que os organismos nacionais ou internacionais interessados pela aprendizagem da escrita utilizem o adjetivo "funcional" e, por sua vez, Vigotski, filósofo da linguagem, use o substantivo "função"? Os dois termos, de fato, relacionam-se à capacidade da língua de veicular a "significação".

Se a língua falada é autônoma por operara partir do signo sonoro constituído de fonemas, aceitemos o postulado segundo o qual é autônoma também a língua escrita, já que ela opera baseada no signo gráfico constituído de caracteres. É espantoso que essa última instância seja ignorada pela maioria das pesquisas e pelos métodos de aprendizagem vigentes no Brasil 6 .

Nossa experimentação mostra que a iniciação da criança na funcionalidade do código tipográfico não somente é possível - as educadoras não querem voltar à caixa única -, mas é desejável, na medida em que

${ }^{5}$ Reservamos o termo "código" ao funcionamento de um conjunto de elementos que impactam o significado. As letras do alfabeto, apenas relacionadas a sons, desprovidas de função discursiva, nesse sentido, não constituem um código. Elas são apenas elementos do sistema alfabético.

${ }^{6} \mathrm{Na}$ França existe uma prática "ideográfica" desenvolvida pela Associação Francesa de Leitura, liderada por Jean Foucambert. 
favorece a emergência de uma consciência gráfica que conduza à apropriação do signo visual.

Ao contrário, a consciência fonológica, objeto de tantas pesquisas, baliza a relação dos grafemas visíveis com o signo sonoro mediante unidades acústicas da língua falada, os fonemas, possibilitando um acesso "caótico" ao significado. Assim, ela opera fora do vínculo direto da grafia com o significado. Esse afastamento entre a grafia e a compreensão - entre o visivel e o legivel (CHRISTIN, 2011, p. 52) - é correlato ao déficit em compreensão apontado na prática da escrita dos jovens pelas avaliações nacionais e internacionais. Se quisermos que os cidadãos de amanhã saibam utilizar a língua escrita como instrumento da vida cotidiana nas suas diversas funções simbólicas, devemos ensiná-la por meio da função discursiva enraizada no signo gráfico.

Formulamos o desejo de que essa proposta centrada no sentido possa oferecer a todos os brasileiros - já que foi experimentada em meios populares - uma metodologia rumo ao domínio de uma língua escrita autêntica, articulada ao legível.

Os jovens da classe média se beneficiam na sociedade e na família de uma cultura que lhes permite encontrar um caminho alternativo rumo à compreensão, qualquer que seja o método oferecido pela escola. Por outro lado, as crianças oriundas da periferia das cidades não podem contar com a alternativa da cultura familiar, tornando-se cativas do percurso escolar. Por serem mais tributárias do método fonológico oferecido pela escola, elas são mais expostas ao risco do analfabetismo funcional.

Nossa experimentação mostra que crianças de classes populares se apropriam da compreensão da escrita quando o significado do signo gráfico não se perde ao longo da aprendizagem. A abordagem alternativa aqui descrita possibilita que as jovens gerações compreendam antes de pronunciar, em vez de pronunciar sem compreender, ou de escrever como pronunciam. 


\section{Referências}

ALAIN, (CHARTIER Émile-Auguste, dito). Reflexões sobre a educação. São Paulo: Saraiva, 1978.

ARENA, Dagoberto Buim. Gestos para escrever em documentos oficiais franceses. In: $11^{\circ}$ ENCONTRO DE PESQUISA EM EDUCAÇÃO DA REGIÃO SUDESTE, 2014, São João Del Rei. Anais... São João Del Rei: Universidade Federal de São João Del-Rei, 2014. p. 1-10. Disponível em: <https://anpedsudeste2014.files.wordpress.com/2015/07/dagoberto-buimarena.pdf>. Acesso em 18 out. 2015.

BAJARD, Élie; ARENA, Dagoberto Buim. Por uma aprendizagem do ato de ler et escrever em um sistema tipográfico. In: DAVID, Célia Maria et al. (Org.). Desafios contemporâneos da Educação. São Paulo: Cultura Acadêmica, 2015 pp. 251-276.

Disponível em: $\quad \leq$ https://www.google.com.br/search?q=PISA\&ie=utf-8\&oe=utf8\&gws $r d=c r \& e i=i U o i V p P F J 40 r w g T d 0 o \_w D Q \# q=D e s a f i o s+$ contempor\%C3\%A2ne os+da+Educa\%C3\%A7\%C3\%A3o+dagoberto>. Acesso em 17 out. 2015.

BAJARD Élie. Manifesto dos usuários da escrita. Ensino em Re-Vista. Uberlândia, v. 21, n. 01, jan./jun. 2014. Disponível em: <http://www.seer.ufu.br/index.php/emrevista/issue/view/1024>. Acesso em: 06-022014.

A descoberta da língua escrita. São Paulo: Cortez, 2012.

Da escuta de textos à leitura. São Paulo: Cortez. 2007.

BAUDELOT C., ESTABLET R. L'élitisme républicain. L'école française à l'épreuve des comparaisons internationales. Paris: Seuil, 2009.

CAPOVILLA, Alessandra G.S., \& CAPOVILLA, Fernando, C. Alfabetização: Método fônico. São Paulo: Silvana Santos, 2002.

CAPOVILLA, Fernando, C., (Org.). Os novos caminhos da alfabetização infantil. Relatório encomendado pela Câmara dos Deputados ao Painel Internacional de Especialistas em Alfabetização Infantil. São Paulo: Memnon, 2005.

CHRISTIN, Anne Marie. L’invention de la figure. Paris: Flammarion, 2011.

DERRIDA, Jacques. A gramatologia. São Paulo: Perspectiva, 1999.

FERREIRO, Emília; TEBEROSKY Ana. Psicogênese da língua escrita. Porto Alegre: Artes Médicas, 1991. 
FOUCAMBERT, Jean. "N'insistez pas Stanislasssss!".Les Actes de Lecture. Mars 2008, n ${ }^{\circ} 101$, pp. 28-44.

SAENGER, Paul. "A leitura nos séculos finais da Idade Média”. In: CAVALLO, Guglielmo, CHARTIER Roger (Orgs.). História da leitura no mundo ocidental. Tradução de Fulvia M. L. Moretto. São Paulo: Ática, 1998, v. 1, p.147-184.

SAUSSURE, Ferdinand. Curso de linguística geral. São Paulo: Cultrix,1969.

SMITH, Frank. Leitura significativa. Porto Alegre: Artes Médicas, 1999.

VIGOTSKI, Liev S. A construção do pensamento e linguagem. São Paulo: Martins Fontes, 2010.

\section{Sites citados :}

INEP.<http://inep.gov.br/educacaobasica/prova_brasil_saeb/resultados/2013/ caderno prova brasil 2013.pdf $>$.Acesso em 30/01/2015.

IPM.<http://www.ipm.org.br/download/inaf01.pdf. Acesso em 30/01/2015>. PISA.<http://educacao.uol.com.br/noticias/2013/12/03/pisa-desempenho-do-brasilpiora-em-leitura-e-empaca-em-ciencias.htm>. Acesso em 23/01/2014.

Recebido em 15 de fevereiro de 2015. Aprovado em 08 de outubro de 2015. 